\title{
Economic modelling as a tool to support macroalgal bloom management: a case study (Sacca di Goro, Po river delta)
}

\author{
Un modèle économique comme outil de gestion d'une floraison \\ macroalgale. Un cas d'école : la Sacca di Goro dans le delta du Pô
}

\author{
Francesca Cellina ${ }^{\text {a }}$, Guilio A. De Leo ${ }^{\text {a,b, } * \text {, Andrea E. Rizzoli }}{ }^{\mathrm{c}}$, \\ Pierluigi Viaroli ${ }^{\text {a }}$, Marco Bartoli ${ }^{\text {a }}$ \\ ${ }^{a}$ Dipartimento di Scienze Ambientali, Università degli Studi di Parma, Parco Area delle Scienze 33/A, 43100 Parma, Italy \\ ${ }^{b}$ Agenzia Regionale per la Protezione Ambientale, Via Restelli 1, 20124 Milano, Italy \\ c Istituto Dalle Molle di Studi sull'Intelligenza Artificiale, Galleria 2, 6928 Manno, Switzerland
}

Received 31 July 2002; accepted 30 September 2002

\begin{abstract}
During the last 20 years, intensive mollusk farming has been developed in coastal waters, mostly in sheltered bays and lagoons. Often, mollusk stocks are threatened by frequent anoxic events from macroalgal blooms. Here, a decision support tool is described to select the optimal short-term strategy to control algal biomasses. Even though long-term and detailed studies of the lagoon systems are required to provide reliable, biologically based policies, we have here developed a simplified analysis that overlooks most of the ecological complexity, but explicitly includes environmental variability and uncertainty in parameter estimation in the economic assessment of the performances of different management strategies. The aim is to quickly screen management alternatives of harvesting Ulva rigida biomass in terms of the control measures considered, i.e. the number of vessels used (the harvesting effort) and the $U$. rigida density at which the vessels start to operate. The decision support tool was applied to the Sacca di Goro, the southernmost coastal lagoon of the Italian Po river delta, where intensive farming of the clam Tapes philippinarum occurs. The results of the analysis indicate that an intermediate number of vessels should start operating as soon as $U$. rigida biomass exceeds low thresholds.
\end{abstract}

(C) 2003 Éditions scientifiques et médicales Elsevier SAS and Ifremer/CNRS/IRD. All rights reserved.

\section{Résumé}

Ces vingt dernières années, l'aquaculture des mollusques s'est intensifiée dans les eaux côtières, particulièrement dans des baies abritées et des lagunes. Souvent, les mollusques sont perturbés par des crises anoxiques liées à des floraisons macroalgales. Nous décrivons un outil de décision permettant de choisir la meilleure stratégie à court terme pour contrôler la biomasse des algues. Même si des études détaillées à long terme des systèmes lagunaires sont nécessaires pour définir une politique durable basée sur la biologie, nous présentons ici une analyse simplifiée qui s'affranchit d'une bonne part de la complexité écologique, mais qui inclut la variabilité de l'environnement et l'incertitude de l'estimation des paramètres dans l'approche économique des performances des différentes stratégies de gestion. L'objectif est d'examiner rapidement les scénarios de ramassage d'Ulva rigida en termes de nombre de navires utilisés (effort de pêche) et de densité d'U. rigida à laquelle les navires cessent de travailler. Cet outil de décision a été appliqué au Sacca di Goro, la lagune la plus au sud du delta du Pô, siège d'une aquaculture intensive de Tapes philippinarum. Les résultats montrent qu'un nombre intermédiaire de navires doit commencer l'opération aussitôt que la biomasse d'U. rigida dépasse les seuils bas.

(C) 2003 Éditions scientifiques et médicales Elsevier SAS and Ifremer/CNRS/IRD. Tous droits réservés.

Keywords: Algal bloom management; Bioeconomic analysis; Stochastic modelling; Ulva rigida; Tapes philippinarum

Mots clés : Gestion d'une floraison macroalgale ; Analyse bio-économique ; Modélisation stochastique ; Ulva rigida ; Tapes philippinarum

* Corresponding author.

E-mail address: deleo@dsa.unipr.it (G.A. De Leo). 


\section{Introduction}

Increasing pressure on coastal areas from land use change, sewage discharge and agricultural chemicals are conflicting uses with the preservation of ecological integrity, the conservation of recreational use and the development of economic activities such as fisheries and mollusk farming (Charlier and Lonhienne, 1996). Eutrophication and intensive aquaculture in coastal lagoons created suitable conditions for the blooms of macroalgae in several coastal lagoons and bays in the last 20 years (Sfriso et al., 1992; Borum, 1996; Castel et al., 1996; Flechter, 1996; Morand and Briand, 1996; Solidoro et al., 1997; Valiela et al., 1997; Raffaelli et al., 1998). Algal blooms are particularly noxious, as the consequent anoxic crises lead to massive mortality of clam with resultant economic damages to the mollusk fishery.

Lagoon managers have a suite of different strategies to manage these problems (Charlier and Lonhienne, 1996; Scheffer, 1998). Long-term, comprehensive policies that target reduction of nutrient loading from agriculture and sewage systems require large investments, long implementation times and a coordinated land planning strategy with different public bodies governing the territory.

On the contrary, lagoon managers often rely on mediumto short-term policies that focus on the limitation of the damages from blooms rather than on the causes that trigger them. For instance, channels can be dredged in a lagoon to improve hydrodynamics and thus reduce the risk of anoxia. However, while dredging must be planned far in advance, the direct removal of algal beds with special vessels can be performed almost in emergency conditions with little or no planning and a fairly limited cost and, thus, it has become the preferred short-term strategy for algal bloom control. This strategy can be considered effective if it is able to avoid algal collapses and the consequent economic damages to aquaculture. The actual ability to control algal blooms depends upon the number of the vessels used, their harvesting efficiency and the threshold of macroalgal biomass above which the vessels start to operate. Other variables, such as macroalgal growth rate and nutrient availability in the water column, and several physical factors, water temperature, light intensity, wind, currents, waves - which may be important determinants of algal growth-cannot be controlled by the lagoon managers. Harvesting costs obviously increase with the number of vessel-days and their actual value depends also upon the rental rate of vessels, man-power and the costs of disposal of the harvested biomass. These costs should be compared to the benefits measured in terms of avoided economic losses of commercial yield that would be otherwise caused by algal blooms and the consequent anoxic crises. Unfortunately, despite the widespread use of these short-term strategies, the effectiveness of this policy has been rarely assessed in a quantitative framework of a cost-revenue analysis.

The Sacca di Goro-a large shallow coastal lagoon (surface: $26 \mathrm{~km}^{2}$; average depth: $1.5 \mathrm{~m}$ ) located on the southern

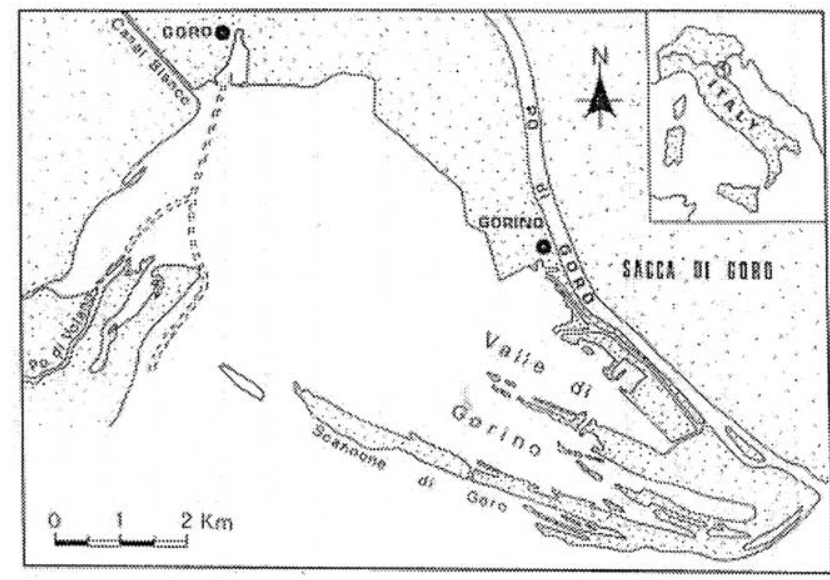

Fig. 1. Sacca di Goro map and its position in Northern Italy.

Po river delta in Italy Fig. 1) - is an interesting testing ground to assess the economic efficiency and the efficacy of harvesting Ulva to control algal blooms. The Sacca di Goro has four nutrient-rich freshwater inlets (Po di Volano and Po di Goro rivers and Bianco and Giralda channels) and is separated from the sea by a narrow sandy barrier. There are two openings to the Adriatic Sea of ca. $1 \mathrm{~km}$ in width. Since the late 1980s, the introduction of the exotic clam species Tapes philippinarum has locally enhanced the mollusk fishery, which still has not recovered since the great economic turndown of the late 1970s and the resultant market collapse (Carrieri et al., 1992). Today clam fishery covers an area of $10 \mathrm{~km}^{2}$ and is concentrated in the south-central part of the lagoon. Average income from shellfish production is ca. 50 million euros, distributed among a 1000 local people, who depend directly or indirectly on the fishery (Bencivelli, personal communication).

As for many eutrophic coastal environments, nutrient loads have led in the Sacca di Goro to the disappearance of rooted macrophytes and the appearance of opportunistic floating macroalgae. During winter and early spring, due to low biomass, these algae drift within the lagoon, whilst above 3-400 $\mathrm{g} \mathrm{DW} \mathrm{m}^{-2}$, they stand and accumulate in the shallower sites. Water stagnation due to Ulva beds has dramatic implications for clams, leading to extended mortality and considerable economic losses.

Lagoon managers' attempts of direct intervention have centred on harvesting Ulva with two vessels rented from a third part company. The number of vessels and operational mode are usually constrained by budget limitation on a year to year basis. The aim of this work is to assess the effectiveness and the efficacy of this policy, namely to: (i) evaluate its ability to control algal blooms; (ii) assess whether this policy is also economically effective, namely whether on average the benefits exceed the costs, and with what frequency; (iii) identify possibly more effective policies of Ulva harvesting, if any, in terms of number of vessels used and their harvesting intensity, under a variety of scenarios, including lower renting costs of vessel-days and the acquisition of a own fleet instead of renting vessels from third part companies. 
Previous works (De Leo et al., 2002; Cellina et al., 2002) provided an initial quantitative analysis of the effects of the harvesting policy. The distinct feature of the modelling effort has been the explicit inclusion of environmental variability, a structural feature of algae dynamics in such an ephemeral environment that severely impacts the actual success of any given management policy. The inclusion of this aspect allows to assess not only the average net benefits of any given policy but also its dispersion and probability distribution. The present work extends those preliminary analyses by (a) considering a model of Ulva dynamics that better describes algal blooms; (b) a more realistic description of the harvesting efficiency function of the vessels; (c) a more precise accounting of costs for harvesting and disposal; (d) a more comprehensive analysis of harvesting scenarios (net economic performances as a function of the vessel renting costs).

This work is structured to (i) present the basic Ulva demography in the Sacca di Goro, (ii) derive a simple stochastic model of population dynamics, (iii) describe the economic parameters and control variables to specify a policy, (iv) analyse traditional harvesting practice and other harvesting strategies by evaluating harvesting intensity and temporal distribution and (v) finally to discuss how to control algal blooms in a cost-effective way.
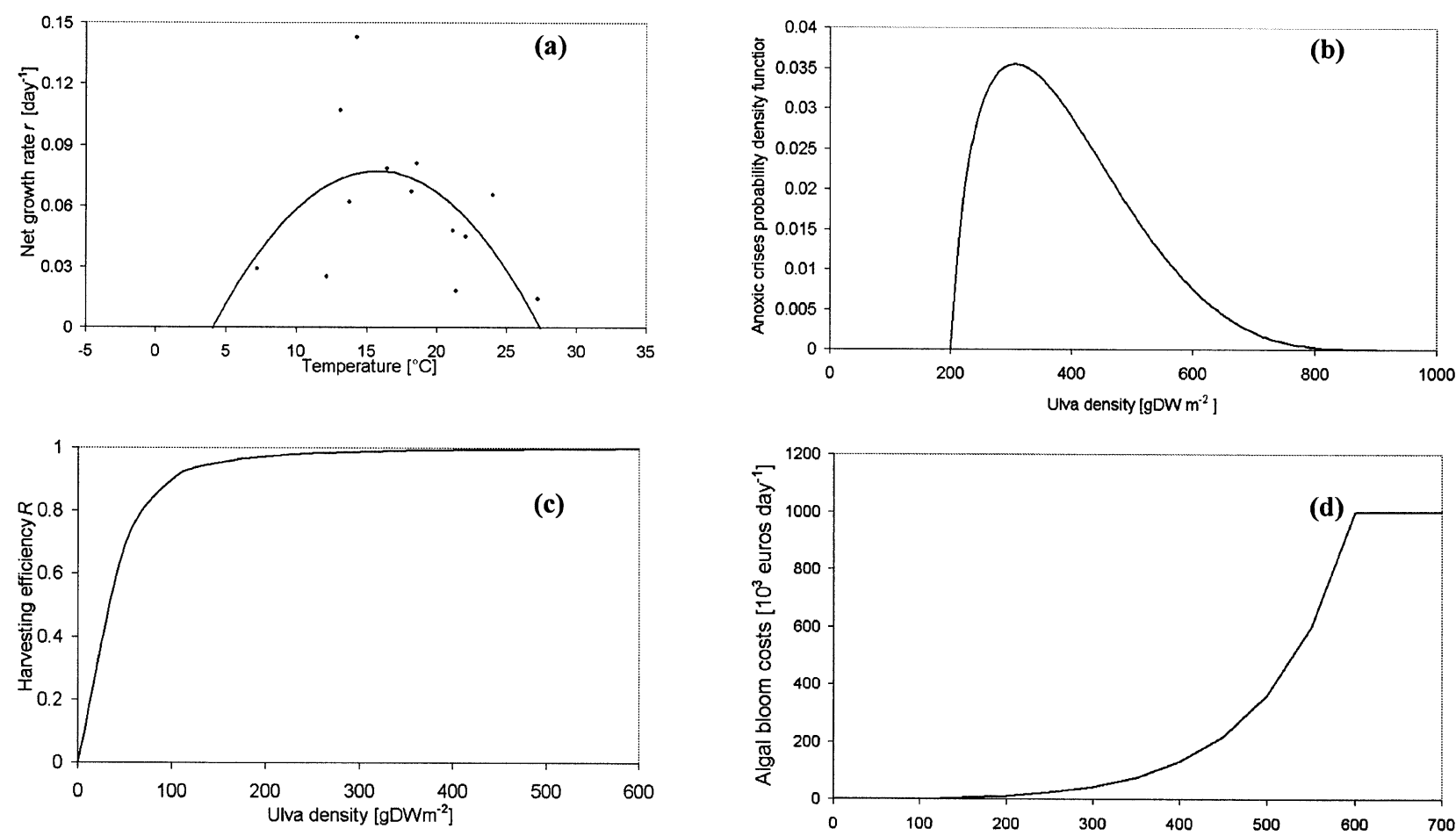

\section{The population dynamics of Ulva biomass}

\subsection{Ulva growth rate}

As evidenced in Fig. 2a, water temperature can certainly be considered one of the most important influential factors of algal growth rate in a nutrient-rich environment, along with nutrient availability, light, hydrodynamics and densitydependent controls (Lobban and Harrison, 1994; Viaroli et al., 1996, 2001).

Data on water temperature and algal growth used in this work have been sampled during research activities carried out in Sacca di Goro in 2 years, 1994 and 1997 (Clean Project, 1994 and Robust and Nice, 1997). The first year was characterised by a fairly low Ulva abundance, whilst the second by a high biomass presence and an impressive algal bloom. Unfortunately, no other quantitative information was available for the reference years to directly correlate algal growth with other variables such as nutrient concentration in the water column and in the sediment. On the other hand, because of the hypertrophic conditions of the lagoon due to the high nutrient load from the freshwater inlets and the sediment-associated regeneration (Bartoli et al., 1996, 2001), nutrients cannot be considered the most important limiting

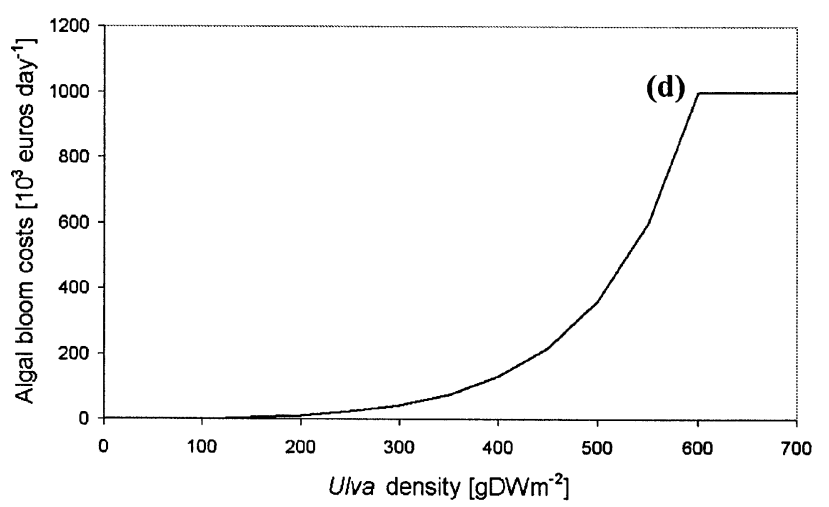

Fig. 2. (a) The relation between water temperature and Ulva growth rate. The black dots represent observed data in 1994 and 1997 and the line the parabolic interpolating function. (b) The beta probability density function for the eutrophication threshold $A_{\text {eu }}$, as calibrated from field data. (c) The harvesting efficiency saturation function of a vessel, with respect to algal density. (d) The economic losses related to algal blooms, with respect to algal density, as estimated by De Leo et al. (in press). 
factor in Goro, thus making temperature probably the most important driving force of algal growth as first approximation.

According to Lobban and Harrison (1994), a parabolic function of water temperature $T$ provides the best fit to the present data for the daily growth rate $\mathrm{r}$ of Ulva, namely

$$
\begin{gathered}
r(T)=0.00057 T^{2}+0.017942 T-0.06398+ \\
W G N(0,0.0034)
\end{gathered}
$$

where WGN is a White Gaussian Noise with mean equal to zero and variance estimated by means of a non-linear least square estimator on available data along with the other parameters. In the simulation phase described in the following, the WGN allows us to explicitly account for the dispersion of algal growth rate from its expected mean for any given temperature: this is a very important component of the model, as dispersion is likely due to other factors, such as nutrient availability, which we could not include in the model.

As available data only cover the first 7 months of the year, relation (1) has been assumed representative of the dependence of Ulva growth rate only between 1 January and 31 July.

\subsection{The daily water temperature model}

Daily temperature $T$ has been estimated through an autoregressive model on residual components as the difference between the observed and the expected average daily temperature (Melià, 2001), namely

$\hat{T}(t+1)=T_{\text {exp }}(t+1)+\alpha\left(T_{\text {obs }}(t)-T_{\text {exp }}(t)\right)$ $+W G N(0.09)$

where $T_{\mathrm{obs}}$ stands for the observed average daily temperature and $T_{\exp }$ for the expected average daily temperature, estimated as

$$
T_{\text {exp }}(t)=f^{*} \sin \left(\frac{2 \pi}{365}(t+e)\right)+g
$$

As documented in Melià (2001), the parameters $a(-0.92$, $P<0.01), f\left(-9.76 \pm 0.07{ }^{\circ} \mathrm{C}\right), e(=-114.74 \pm 0.42 \mathrm{~d})$, the mean annual temperature $g\left(-16.35 \pm 0.05^{\circ} \mathrm{C}\right)$ and the White Gaussian Error were calibrated on a long series of water temperature data monitored in Sacca di Goro (1993-1995).

\subsection{The biological model: the anoxic crises}

When a eutrophication threshold density of Ulva $A_{\text {eu }}$ is exceeded, algal biomass drops in the shape of a collapse (Viaroli et al., 2001). As shown in Table 1, reporting data from Viaroli et al. (2001), the Ulva biomass $A_{\text {eu }}$ triggering the anoxic crises ranges between 200 and $900 \mathrm{~g} \mathrm{DW} \mathrm{m}^{-2}$ (mean value around $300 \mathrm{~g} \mathrm{DW} \mathrm{m}^{-2}$ ). When the collapse and the consequent anoxic crises occur, phytoplankton become the dominant primary producers for several weeks, during which the macroalgal density is very low (Viaroli et al., 2001). According to Zaldivar et al. (2003), only about 2 months later, Ulva starts to increase at a detectable rate.

In order to take into account the natural variability characterising the dystrophic events, we assumed a bloom density $A_{\text {eu }}$ as a random beta probability distribution calibrated on data reported in Table 1. Accordingly, algal dynamics can be represented by means of a set of difference equations with a daily simulation step, namely:

$A_{t+1}=\left\{\begin{array}{c}\lambda\left(T_{t}\right) A_{t} \quad \text { if } A_{t}<A_{e u} \\ 0.2 \quad \text { if } A_{t} \geqslant A_{e u} \text { and for } 60 \text { days after the last algal bloom }\end{array}\right.$

where $A_{\mathrm{t}}$ is dry weight (DW) Ulva biomass $\left(\mathrm{g} \mathrm{DW} \mathrm{m}^{-2}\right.$ ) on day $t, \lambda(T)=\exp \left(r_{T}\right)$ and $A_{\text {eu }}$ is drawn from the beta probability function $\beta(a, b, p, q)$, where $a=1.6, b=4.5, p=$ $200 \mathrm{~g} \mathrm{DW} \mathrm{m}^{-2}$ and $q=900 \mathrm{~g} \mathrm{DW} \mathrm{m}^{-2}$ have been estimated on available data (see Fig. 2b.

With respect to much more complex models of a lagoon ecosystem developed for Goro (Zaldivar et al., 2003) and other north Adriatic lagoons (Solidoro et al., 1997), our zero-dimensional model (4) should be regarded as a "black box" whose purpose is not to give a detailed mechanistic description of the biological process of Ulva growth, but rather to provide a sufficiently realistic short-term simulation of algal blooms in terms of frequency, timing and intensity, so as to assess the economics of Ulva harvesting. As a formal validation was not possible because of lack of data, a qualitative assessment following the Bayesian approach (Hilborn and Mangel, 1997) was carried out by interviewing the lagoon managers. They stated the model was good enough to reproduce the main features (Bencivelli, personal communication) and consequently we accepted the model.

\section{The harvesting process}

\subsection{The traditional management policy}

The present strategy to control algal blooms relies on harvesting vessels rented from a third part company. Specifically, the lagoon managers sign a contract at the beginning of the year to rent two vessels that are then used jointly along the Ulva growing season for no more than $10-15 \mathrm{~d}$. The vessels only operate in the area where clam fishery is located. Each vessel-day costs as much as 2000 euros all inclusive (vessels, workers, fuel, insurance and the transport of Ulva to the disposal centre). Only the effective number of days in which vessels are actually used is then paid to the renting

Table 1

Monitored values for $A_{\mathrm{eu}}$, the eutrophication Ulva density value triggering the anoxic crises (field campaigns from 1990 to 1997 )

\begin{tabular}{llllllll}
\hline Year & 1990 & 1991 & 1992 & 1993 & 1994 & 1995 & 1996 \\
\hline Monitored $A_{\text {eu }}\left(\mathrm{g} \mathrm{m}^{-2}\right.$ year $\left.^{-1} \mathrm{DW}\right)$ & 500 & 300 & 400 & 250 & 350 & 300 & 300 \\
\hline
\end{tabular}


company, but it rarely happens that vessels operate for less days than planned at the beginning of the year. As a consequence, 40,000-60,000 euros are usually required every year for two vessels for 10-15 d. The actual number of harvesting days indicated in the contract may change from year to year and depends upon budget availability. The lagoon managers then bear the responsibility to decide when to use the vessels, within the limitation of renting days. Given the limited budget available, the vessels should be used carefully, as if they are used too often at the beginning of the season, no spare days are left to be used to control subsequent algal blooms. For this reason, the lagoon managers tend to be very conservative, using the vessels only when Ulva biomass starts to attain a threatening density and the rate of increase is clearly high.

\subsection{The harvesting model}

The Ulva biomass harvested by one vessel per unit time depends on vessel size, harvesting equipment and Ulva abundance. Interviews with the lagoon managers suggested that the harvesting efficiency $R$ decreases when algal density is low. This can be satisfactorily represented by a sinusoidal saturating function of Ulva density (Fig. 2c), namely

$$
R(A)=\frac{A^{2}}{A^{2}+\delta}
$$

where the semi-saturation constant $\delta$ was set to 1125 $\left(\mathrm{g}^{2} \mathrm{DW} \mathrm{m}^{-4}\right)$ (Bencivelli, personal communication). According to this representation, harvesting efficiency results negligible for very low Ulva abundance, as the macroalgae patches are widely scattered in the lagoon; then, the efficiency increases for increasing algal density, and, finally, it levels off to a maximum daily harvesting capacity $q$ (g DW $\mathrm{m}^{-2}$ ) which was estimated to be $10 \mathrm{~g} \mathrm{DW} \mathrm{m}^{-2} \mathrm{~d}^{-1}$ (Viaroli and Sartore, 1997).

\subsection{The economic losses related to algal blooms}

The economic losses due to algal blooms (i.e. the indirect costs) were identified in a previous work by De Leo et al. (2002), who assumed monetary damages to the Tapes rearing activity to be dependent on algal density and estimated them on a daily basis; the estimate only refers to the direct loss of incomes and does not provide any reference to the value of the ecosystem services. They stated that no economic losses occur when algal density is below $100 \mathrm{~g} \mathrm{DW} \mathrm{m}^{-2}$ and that losses reach their maximum $\left(1000 \times 10^{3}\right.$ euros $\left.\mathrm{d}^{-1}\right)$ when Ulva density exceeds $600 \mathrm{~g} \mathrm{DW} \mathrm{m}^{-2}$, due to the massive clam mortality caused by the anoxic crises. For intermediate values of algal biomass, only a fraction of the commercial yield is lost every day, and consequently economic losses increase with Ulva density according to an exponential relation, as Fig. 2d shows. This model has been here adopted to estimate daily monetary damages to lost clam production.

\section{The final management model}

Let $E$ be the number of vessels used to harvest algal biomass and $A_{\mathrm{th}}\left(\mathrm{g} \mathrm{DW} \mathrm{m}^{-2}\right)$ the threshold density of Ulva, which, if exceeded, triggers harvesting operations. Under the previous assumptions, the equation describing the Ulva dynamics is

$A_{t+1}=\left\{\begin{array}{cc}\lambda(T) A_{t} & \text { if } A_{t}<A_{t h} \\ \lambda(T) A_{t}-q E R\left(A_{t}\right) & \text { if } A_{t h}<A_{t}<A_{e u} \\ A_{\text {reset }}=0.2 & \text { if } A_{t}>A_{e u} \text { and for } 60 \text { days after the last algal bloom }\end{array}\right.$

Equation (6) is the core of the simulation model of the Ulva harvesting process: it states that every day a decision is taken whether to harvest or not: if the algal density exceeds the threshold $A_{\mathrm{th}}, E$ vessels will harvest biomass for the entire working day. The following day, a new decision has to be taken about whether to harvest or not on the basis of actual Ulva biomass.

In our modelling framework, we have assumed that the decision variables are (a) the number of vessels $E$ (vessels) and (b) the threshold density of Ulva $A_{\mathrm{th}}\left(\mathrm{g} \mathrm{DW} \mathrm{m}^{-2}\right)$ which, if exceeded, triggers harvesting operations. We thus define as management policy a combination of these two control variables. According to the contract currently signed up between the lagoon managers and the third part company, the number of vessels and harvesting days is set at the beginning of the year and it does not change during a simulation. For instance, a management policy with $E=4$ vessels and $A_{\text {th }}=$ $100 \mathrm{~g} \mathrm{DW} \mathrm{m}^{-2}$ means that four vessels are sent out in the lagoon to harvest Ulva each day in which its density exceeds $100 \mathrm{~g} \mathrm{DW} \mathrm{m}^{-2}$. Our analysis examined all the management policies generated by combinations of $E$ and $A_{\mathrm{th}}$ ranging between 0 and 20 vessels and 50 and $200 \mathrm{~g} \mathrm{DW} \mathrm{m}^{-2}$, respectively. The discretisation range of $E$ is made by intervals 1 unit wide, and the range of $A_{\mathrm{th}}$ of intervals 25 units wide.

For each management policy, in order to explicitly include environmental variability and uncertainty in parameter estimation, we performed a series of Monte Carlo stochastic simulations between 1 January and 31 July with a 1-d simulation step. Each simulation has been replicated 10,000 times, during which different realisations of the temperature series, of the growth rate and of the $A_{\mathrm{eu}}$ value occurred; moreover, to take into account variability in the Ulva density values of the first few days of the year, the initial density value was extracted from a uniform probability distribution ranging between 0 and $20 \mathrm{~g} \mathrm{DW} \mathrm{m}^{-2}$, which was identified on the basis of the data gathered from 1989 to 1998 (Viaroli et al., 2001).

The management policies have been evaluated with respect to harvesting costs and economic damages due to algal blooms. The two types of costs previously identified are regarded as equally important and consequently the annual cost is the algebraic sum of daily direct costs (the harvesting costs) and the daily indirect costs (the damages caused by the algal blooms). 
Thanks to the Monte Carlo simulations, we have been able also to compute a number of statistics on the economic and biological variables, such as the expected values of the different components of the cost, their standard deviation and the expected number of anoxic crises.

\section{Results and discussion}

\subsection{The present scenario}

The outcomes of simulations corresponding to the current rental cost of 2000 euros for a vessel-day are summarised in Fig. 3a. The most striking result is that no policy is expected to perform in average significantly better than the do-nothing alternative, even when a substantial number of vessels remove Ulva. This occurs because the drop of algal bloom damages obtained by removing Ulva is more than compensated by the increase in harvesting costs, as shown in Fig. 3b,d On the other hand, the elimination of anoxic crises obtained with a sufficiently high number of vessel-days (see Table 2 allows for a significant reduction of variance of overall costs imposed on fishermen because of algal blooms. This is a very important economic parameter, as low volatility of costs allows lagoon managers to plan expenses from year to year better and to avoid the risk of incurring in fairly rare but catastrophic events that are particularly noxious for the commercial fishery. Moreover, further analysis shows that the $95^{\circ}$ upper percentiles of cost distribution are much lower than in the case of the do-nothing alternative. In this sense, the do-nothing alternative cannot be regarded as the optimal policy, even though its mean economic performance is not worse than that of policies of direct intervention. Harvesting Ulva with a suitable number of vessels operating at low algal density can thus be considered better than the do-nothing alternative because of the lower variance of expected costs and substantially negligible probability of extreme events Fig. 3c.

Another important result is that management policies based on lower threshold density $A_{\text {th }}$ are generally more effective (in controlling algal blooms) and more efficient (in economic terms) than policies that delay intervention. If threshold density is larger than $100 \mathrm{~g} \mathrm{DW} \mathrm{m}^{-2}$, there is no way of controlling most of the algal blooms. As a consequence, the sooner the vessels start to operate, the better it is.

Moreover, our analysis shows that a low number of vessels implies higher harvesting costs (with respect to the donothing alternative), yet it is not able to avoid algal blooms. This is exactly what happens with the present policy management (two vessels used for $10 \mathrm{~d}$ ), which turns out to be both ineffective in controlling anoxic crises and inefficient in economic terms regardless of the threshold density $A_{\mathrm{th}}$. Moreover, Fig. 3e shows that, in order to control algal blooms, any management policy requires many more vesseldays than the current $10-15$ year $^{-1}$, which are clearly insufficient.
Finally, further analysis shows that if the harvesting season is restricted between 1 March and 31 July under the same harvesting conditions, the economic performances are even worse, which means again that delaying intervention instead of harvesting as soon as the threshold is reached has a strong negative impact on the economic performances.

\subsection{Harvesting at lower cost}

The simulations performed under the current scenario of rental cost of a vessel-day have shown the number of days the vessels need to operate in order to control algal blooms is substantially higher than the 10-15 d planned by the traditional policy. Due to scale economies, it is reasonable to expect that renting vessels for many more days should allow the lagoon managers to make a better deal in the specific rental rate of vessels, namely to find a company offering the harvesting and disposal service at lower prices. We have thus run simulations with lower rental rates. Results are shown in Fig. 3f,g when costs are set at 2/3 of current value. Under this price reduction scheme, most of the policies that are indeed able to control algal blooms are also more economically convenient than the do-nothing alternative, especially for low values of $A_{\text {th }}\left(50-75 \mathrm{~g} \mathrm{DW} \mathrm{m}^{-2}\right)$. As in the previous case, cost variance drops as well to values significantly smaller than the policies, which are not able to control algal blooms. In the case of low intervention threshold, the overall costs can further decrease with the number of vessels (provided $E \geq 6$ ), but the difference is not significant. As the estimation of algal density can be affected by measurement errors, and a small error in the estimation of the algal density during the operative management could lead to significant increases in total expected costs, a safe policy would require 6-10 vessels operating at density as low as $50 \mathrm{~g} \mathrm{DW} \mathrm{m}^{-2}$.

\subsection{Acquiring and running a fleet}

The effective policies identified in the scenario of a lower rental price require a fairly high number of vessels and harvesting days with respect to what is currently planned in the lagoon. On the one hand, this should allow for a negotiation of lower rental prices as discussed in the previous paragraph, but, on the other hand, it makes economic performances strongly dependent on the third part companies managing the vessel market. For this reason, we have analysed the alternative scenario in which the lagoon managers acquire and run their own fleet of vessels to harvest algae.

According to previous estimates (Cellina et al., 2002), the cost of buying one vessel is about 100,000 euros year ${ }^{-1}$, to be financed over 10 years, while harvesting daily costs are assumed to be 500 euros per vessel per day. Simulations of different management policies under the scenario where the managers own the fleet are shown in Fig. 3h With respect to the previous scenarios, an optimal policy can be clearly identified for $A_{\mathrm{th}}=50 \mathrm{~g} \mathrm{DW} \mathrm{m}^{-2}$ and $E=6$ vessels; the expected value of costs is equal to $920 \pm 50 \times \cdot 10^{3}$ euros year $^{-1}$. Anyway, in this case, an error in the estimation of 

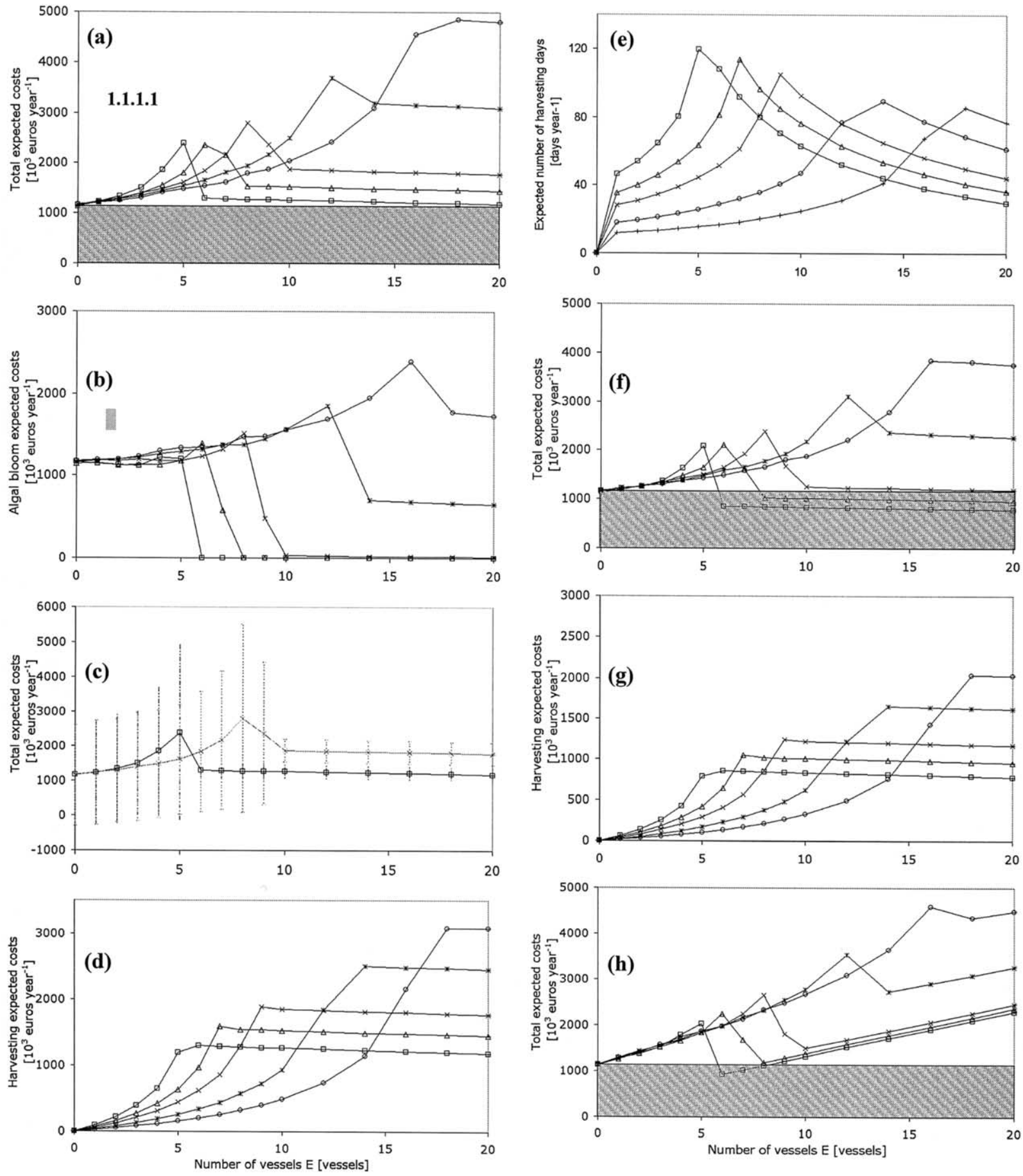

$$
{ }_{\leftrightarrow} A_{t h} 50_{\star} A_{t h} 75_{*} A_{t h} 10_{*} A_{t h} 150_{-} A_{t h} 20 \mathrm{gDW} \mathrm{m}{ }^{-2}
$$

Fig. 3. Simulation results under three different scenarios as a function of the number of vessels used to remove Ulva biomass and five different Ulva threshold density $A_{\text {th }}\left(50,75,100,150\right.$ and $\left.200 \mathrm{~g} \mathrm{DW} \mathrm{m}^{-2}\right)$ above which vessels start to operate. More details are reported in the text. Current scenario: (a) total expected costs; (b) algal bloom expected costs; (c) total expected costs along with their standard deviation; (d) harvesting expected costs; (e) expected number of harvesting days. Harvesting at lower cost scenario: (f) total expected costs; (g) harvesting expected costs. Acquiring and running the fleet scenario: (h) total expected costs. The dashed area highlights the management policies which are more convenient than the do-nothing alternative.

the algal density during the operative management could lead to substantial increases in total expected costs, thus negating the benefits of this strategy. Moreover, the marginal benefits of owning a fleet with respect to the previous scenario of lower rental price are very low and not significantly different. A randomisation test shows that running their own fleet would be convenient for lagoon managers only with respect to the present management strategy. Therefore, the acquisi- 
Table 2

Expected number of anoxic crises per year with different harvesting policies

\begin{tabular}{|c|c|c|c|c|c|c|c|}
\hline$A_{\mathrm{th}}\left(\mathrm{g} \mathrm{m}^{-2} \mathrm{DW}\right)$ & 25 & 50 & 75 & 100 & 125 & 150 & 200 \\
\hline Do-nothing & 1.00 & 1.00 & 1.00 & 1.00 & 1.00 & 1.00 & 1.00 \\
\hline$E=2$ (vessels) & 1.00 & 1.00 & 1.00 & 1.00 & 1.00 & 1.00 & 1.00 \\
\hline$E=6$ (vessels) & 0.00 & 0.00 & 0.94 & 0.99 & 1.00 & 1.00 & 1.00 \\
\hline$E=10$ (vessels) & 0.00 & 0.00 & 0.00 & 0.00 & 0.78 & 0.99 & 1.00 \\
\hline$E=16($ vessels $)$ & 0.00 & 0.00 & 0.00 & 0.00 & 0.00 & 0.00 & 0.69 \\
\hline
\end{tabular}

tion of a private fleet does not seem to be necessary to the extent the lagoon managers will be able to negotiate suitable renting fares with third part companies for the harvesting boats.

\section{Conclusion}

The present work has outlined several different issues related to Ulva harvesting.

First, policies of direct intervention on algal blooms are effective if they are based on early actions at low intervention thresholds for Ulva biomass. Furthermore, an increase in the number of vessels above current levels is required. Therefore, the goal of a management policy aimed at controlling algal blooms has to be to harvest as much Ulva as soon as possible, i.e. to implement 6-10 vessels that start to operate at $50-75 \mathrm{~g} \mathrm{DW} \mathrm{m}^{-2}$. The mean annual cost of such a policy is not lower than that of the do-nothing alternative (in terms of loss of clam commercial yield); yet stochastic simulations show that its variance is substantially lower and the probability of extreme anoxic events that would jeopardise the commercial yield of entire year almost negligible. In this sense, our stochastic model shows that direct harvesting (if correctly implemented) has to be preferred to the do-nothing alternative, a conclusion that would had not been evidenced by a purely deterministic model.

Second, despite the weaknesses and limitations of our management model, we are confident that the current management policy is inefficient from the economic viewpoint as it is not able to control algal blooms despite investing money in ineffective harvesting operations. In fact, the limited number of vessels and vessel-days available by contract induces lagoon managers to delay intervention up to the point that algal biomass cannot be efficiently controlled anymore.

Third, lower rental prices for vessels should be negotiated by lagoon managers, as policies able to control algal blooms need also to be economically convenient with respect to the traditional management in terms of mean annual cost.

If this is not possible, a more detailed economical analysis should be performed to consider the opportunity to acquire a lagoon fleet instead of renting vessels from third part companies.

Needless to say, in light of the investment and/or rental costs required for efficiently controlling algal blooms, scenarios alternative to Ulva harvesting should be considered such as dredging channels in the lagoon, reducing the organic load, fostering more sustainable practices of clam fisheries.
Of course, our analysis is not exempt from criticisms, which can be mostly focused on the simplicity of the management model. In particular, the lack of data on the Ulva life cycle was a critical aspect in this study. Long-term analyses and field campaigns will definitely reduce uncertainty and also allow for the evaluation of long-term ecological consequences of algal blooms and Ulva harvesting. Unfortunately, long-term field sampling campaigns require time and suitable financial support, not available at the present time, while lagoon managers crave for simple, cost-effective and rapid tools to assess potential strategies and to request financial support. Along with its weakness, our modelling exercise evidences the necessity of reconsidering the current shortterm sectorial sampling strategies, usually focused on isolated compartments (sediment, water column, benthos, macroalgae, clam dynamics), in favour of more comprehensive long-term field campaigns, with sampling schemes also finalised to the design, calibration and validation of quantitative management models.

Despite these limitations, we are confident that our simple black-box approach, explicitly including environmental variability and uncertainty in parameter estimation, provides a fair description, as a first approximation, of the statistical features of algal blooms, in terms of their intensity, frequency and timing, that were necessary for an economic assessment of harvesting strategies. Of course, much more work still needs to be done in the direction already outlined by Scheffer (1998), provided that environmental variability can be explicitly included. This crucial, but often neglected, element of the economic assessment of optimal resource management (Walters, 1986) is in fact completely ignored by purely deterministic models, while the knowledge of the probability distribution of model outcomes, used to assess the convenience of alternative strategies, provides the necessary confidence in the decision process through valuable information also on rare, but potentially catastrophic, events (Clark, 1990).

\section{Acknowledgements}

The authors are indebted to lagoon manager, Silvano Bencivelli (Environmental Office of Ferrara Province), for his help in assessing management costs. The authors also thank anonymous referees who greatly helped to improve the work and carefully revised the manuscript. Part of this research has been supported by the Ministero Italiano delle Politiche Agricole-Sezione Acquacoltura e Pesca. 


\section{References}

Bartoli, M., Cattadori, M., Giordani, G., Viaroli, P., 1996. Benthic oxygen respiration, ammonium and phosphorus regeneration in surficial sediments of the sacca di Goro (Northern Italy) and two French coastal lagoons: a comparative study. Hydrobiologia 321, 143-159.

Bartoli, M., Nizzoli, D., Viaroli, P., Turolla, E., Castaldelli, G., Fano, A.E., Rossi, R., 2001. Impact of a tapes philippinarum farming on nutrient dynamics and benthic respiration in the Sacca di Goro. Hydrobiologia 455, 203-212.

Borum, J., 1996. Shallow waters and land/sea boundaries. In: Jørgensen, B.B., Richardson, K. (Eds.), Eutrophication in Coastal Marine Ecosystems. Coastal and Estuarine Studies. Am. Geophys. Union 52, 179-203.

Carrieri, A., Paesanti, F., Rossi, R., 1992. Risultati dell'introduzione di vongola filippina Tapes philippinarum (Adams \& Reeve, 1950) nella Sacca di Goro (Delta del Po). Oebalia 17, 97-104.

Castel, J., Caumette, P., Herbert, R.A., 1996. Eutrophication gradients in coastal lagoons as exemplified by the Bassin d'Arcachon and the Etang du Prévost. Hydrobiologia, 329.

Cellina, F., De Leo, G.A., Bartoli, M., Viaroli, P., 2002. The control of algal bloom damages to clam yield in a North Adriatic coastal lagoon (Sacca di Goro, Italy). Proceedings of the First Biennial Meeting of the International Environmental Modelling and Software Society, vol. 3. iEMSs Lugano Switzerland, June 24-27, 2002. pp. 479-484.

Charlier, R.H., Lonhienne, T., 1996. The management of eutrophicated waters. In: Schramm, W., Nienhuis, P.H. (Eds.), Marine Benthic Vegetation: Recent Changes and the Effects of Eutrophication. Springer, Berlin, pp. 45-78.

Clark, C.W., 1990. Mathematical Bioeconomics, The Optimal Management of Renewable Resources. Wiley Interscience, New York, NY, USA.

Clean, 1994. Coastal Lagoon Eutrophication and Anaerobic processes, Joint EU Project, contract number EV5V-CT920080.

De Leo, G.A., Bartoli, M., Naldi, M., Viaroli, P., 2002. A first generation stochastic bioeconomic analysis of algal bloom control in a coastal lagoon (Sacca di Goro, Po river Delta). Mar. Ecol. 410, 92-100.

Flechter, R.L., 1996. The occurrence of "green tides"-a review. In: Schramm, W., Nienhuis, P.H. (Eds.), Marine Benthic Vegetation: Recent Changes and the Effects of Eutrophication. Springer, Berlin, pp. 7-43.

Hilborn, R., Mangel, M., 1997. The Ecological Detective: Confronting Models with Data. Princeton University Press, Princeton.
Lobban, C.S., Harrison, P.J., 1994. Seaweed Ecology and Physiology. Cambridge University Press, Cambridge, UK pp. 210-240.

Melià, P., 2001. Modelli di gestione integrata per l'allevamento della vongola filippina (Tapes philippinarum) in ambiente lagunare. Ph.D. Thesis, Università degli Studi di Parma.

Morand, P., Briand, X., 1996. Excessive growth of macroalgae: a symptom of environmental disturbance. Bot. Mar 39, 491-516.

Nice, 1997. Nitrogen Cycling in Estuaries, Joint EU Project, Eloise Network, contract number MAS3-CT96-0048.

Raffaelli, D.G., Raven, J.A., Poole, L.J., 1998. Ecological impact of green macroalagal blooms. Oceanogr. Mar. Biol. Annu. Rev 36, 97-125.

ROBUST, 1997. The Role of Buffering capacities in Stabilising coastal lagoon ecosystems, Joint EU Project, Eloise network, contract number ENV4-CT96-0218.

Scheffer, M., 1998. Ecology of Shallow Lakes. Chapman and Hall, London.

Sfriso, A., Pavoni, B., Marcomini, A., Orio, A.A., 1992. Macroalgae, nutrient cycles and pollutants in the lagoon of Venice. Estuaries 15, 517-528.

Solidoro, C., Brando, V.E., Dejack, C., Franco, D., Pastres, R., Pecenik, G., 1997. Long term simulations of population dynamics of Ulva rigida in the lagoon of Venice. Ecol. Model 102, 259-272.

Valiela, I., McLelland, J., Hauxwell, J., Behr, P.J., Hersh, D., Foreman, K., 1997. Macroalgal blooms in shallow estuaries: controls and ecophysiological and ecosystem consequences. Limnol. Oceanogr 42, $1105-1118$

Viaroli, P., Naldi, M., Bondavalli, C., Bencivelli, S., 1996. Growth of the seaweed Ulva rigida, C. Agardh in relation to biomass densities, internal nutrient pools and external nutrient supply in the Sacca di Goro lagoon (Northern Italy). Hydrobiologia 329, 93-103.

Viaroli, P., Sartore, F., 1997. Effectiveness of macroalgal biomass harvesting in dystrophic lagoons. Proceedings of the Eighth Congress of the Italian Ecological Society (S.It.E.), vol. 18, pp. 493-495.

Viaroli, P., Azzoni, R., Bartoli, M., Giordani, G., Taje', L., 2001. Evolution of the trophic conditions and dystrophic outbreaks in the Sacca di Goro lagoon (Northern Adriatic Sea). In: Faranda, F.M., Guglielmo, L., Spezie, G. (Eds.), Mediterranean Ecosystems: Structures and Processes. Springer Verlag Italia, Milano, pp. 467-475.

Walters, C., 1986. Adaptive Management of Renewable Resources. Macmillan, New York, NY, USA.

Zaldivar, J.M., Cattaneo, E., Murray, C.N., Giordani, G., Viaroli, P., 2003. Long-term simulation in coastal lagoons: Sacca di Goro. Near Shore Oceanography. 